Article

\title{
High-Temperature Compressive Resistance and Mechanical Properties Improvement of Strain-Induced Melt Activation-Processed Al-Mg-Si Aluminum Alloy
}

\author{
Chia-Wei Lin, Fei-Yi Hung * and Truan-Sheng Lui \\ Department of Materials Science and Engineering, National Cheng Kung University, \\ Tainan 701, Taiwan; qqkm0526@gmail.com (C.-W.L.); luits@mail.ncku.edu.tw (T.-S.L.) \\ * Correspondence: fyhung@mail.ncku.edu.tw; Tel.: +886-6-275-7575 (ext. 31395); Fax: +886-6-234-6290 \\ Academic Editor: Nong Gao \\ Received: 13 June 2016; Accepted: 21 July 2016; Published: 5 August 2016
}

\begin{abstract}
Even though the high-temperature formability of Al alloys can be enhanced by the strain-induced melt activation (SIMA) process, the mechanical properties of the formed alloys are necessary for estimation. In this research, a modified two-step SIMA (TS-SIMA) process that omits the cold working step of the traditional SIMA process is adopted for the $6066 \mathrm{Al}-\mathrm{Mg}-\mathrm{Si}$ alloy to obtain globular grains with a short-duration salt bath. The high-temperature compressive resistance and mechanical properties of TS-SIMA alloys were investigated. The TS-SIMA alloys were subjected to artificial aging heat treatment to improve their mechanical properties. The results show that the TS-SIMA process can reduce compression loading by about $35 \%$. High-temperature compressive resistance can be reduced by the TS-SIMA process. After high-temperature compression, the mechanical properties of the TS-SIMA alloys were significantly improved. Furthermore, artificial aging treatment can be used to enhance formed alloys via the TS-SIMA process. After artificial aging treatment, the mechanical properties of TS-SIMA alloys are comparable to those of general artificially-aged materials.
\end{abstract}

Keywords: aluminum alloy; Strain-Induced Melt Activation (SIMA); mechanical properties

\section{Introduction}

6xxx series $\mathrm{Al}$ alloys, a series of precipitation-hardened $\mathrm{Al}$ alloys, are widely used. $6066 \mathrm{Al}$ alloy, used in this study, has a strength that is higher than that of the great majority of other alloys in this series due to its $\mathrm{Cu}$ and $\mathrm{Mn}$ addition and excess $\mathrm{Si}[1,2]$. This alloy is widely applied in the automobile industry, bicycle industry, and architecture components, due to its high strength and low density. Even though $\mathrm{Cu}$ and $\mathrm{Mn}$ increase strength, they decrease formability. In order to promote formability, the strain-induced melt activation (SIMA) process is used for forming at high temperatures.

The SIMA process is a semi-solid process, in which the materials are manufactured at temperatures of solid-liquid coexistence. The finished products have a near-net shape advantage [3-5]. The SIMA process has great potential due to its low cost and high stability [6-10]. Figure 1a shows the procedure of the two-step SIMA (TS-SIMA) process proposed in this study. The steps are: (1) casting, which produces a dendritic structure; (2) hot extrusion, which disintegrates the initial structure and introduces sufficient strain energy into the alloy; and (3) salt bath, which makes the material recrystallize and partially melt at temperatures of solid-liquid coexistence. TS-SIMA is defined as a two-step process because the casting materials are via only two steps to obtain globular grains. The two major differences between the traditional SIMA process and the TS-SIMA process are: (1) the proposed TS-SIMA process uses severe hot extrusion instead of cold work to introduce a large amount of strain energy; and (2) the 
proposed SIMA process uses a salt bath instead of an air furnace to improve heating uniformity and reduce heating time. The globular grain evolution for the proposed TS-SIMA process is shown in Figure $1 b$ [11].

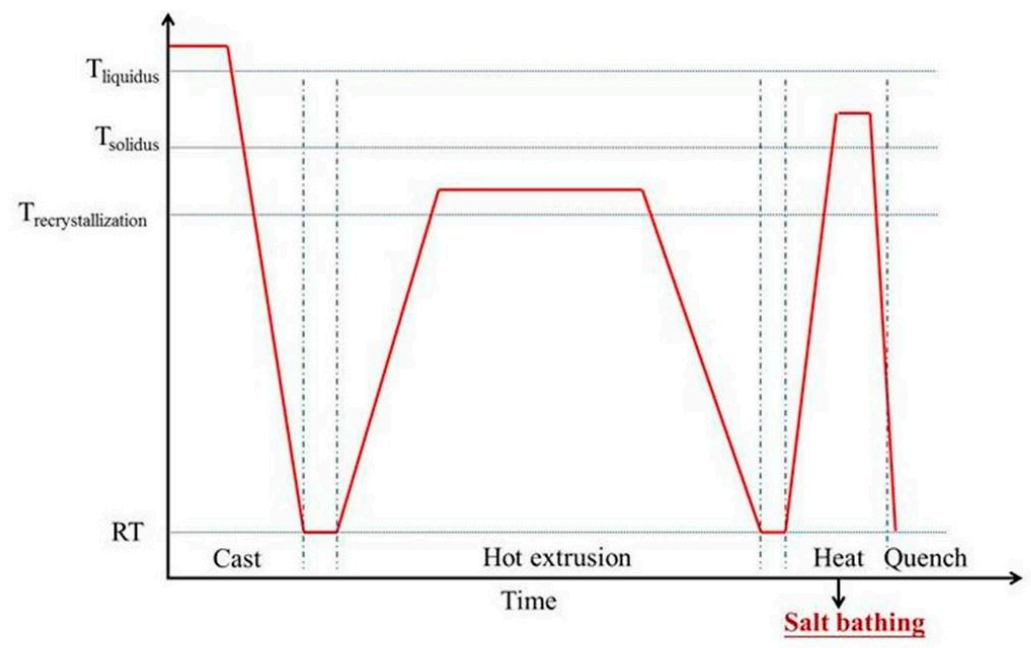

(a)

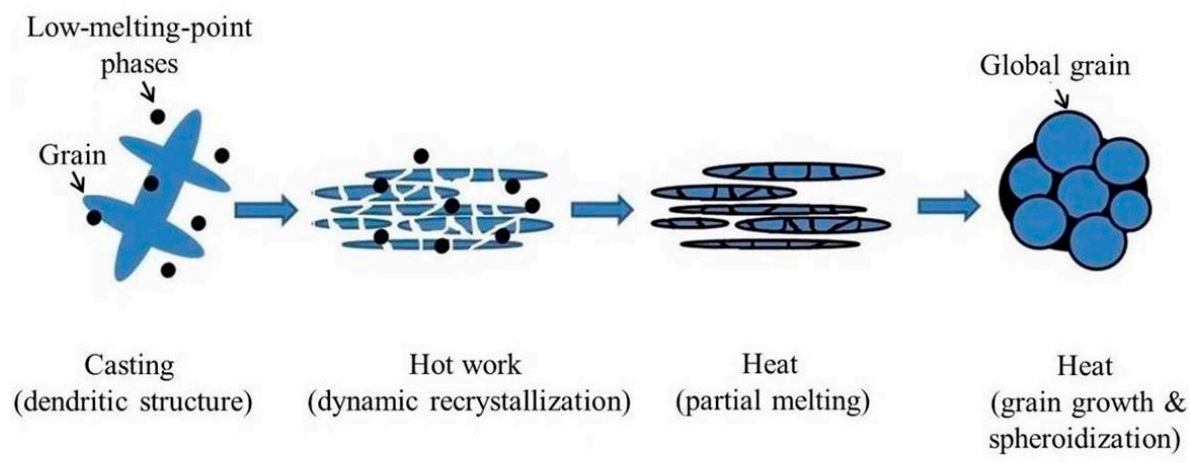

(b)

Figure 1. (a) Procedure of TS-SIMA process and (b) formation steps of globular grains in TS-SIMA process.

In our previous study [11], the high-temperature deformation resistance and forming behavior of TS-SIMA alloys were investigated. The improvement in the high-temperature formability of alloys subjected to the TS-SIMA process was confirmed. However, the mechanical properties of the formed alloys after the TS-SIMA process were not examined. In this research, the high-temperature compressibility and the improvement of the mechanical properties of TS-SIMA alloys are investigated. High-temperature compressibility is evaluated using high-temperature compression. The compression deformation mechanism of TS-SIMA alloys is also investigated. The mechanical properties of TS-SIMA alloys are investigated and improved via artificial aging (T6) heat treatment.

\section{Materials and Methods}

The material used in this study was extruded $6066 \mathrm{Al}$ alloy. Its composition, determined using a glow discharge spectrometer, is shown in Table 1 . Six-inch $(15.24 \mathrm{~cm})$ diameter casting materials were extruded with dimensions of $52 \mathrm{~mm}$ (width) $\times 3 \mathrm{~mm}$ (thickness) and $75 \mathrm{~mm}$ (width) $\times 9 \mathrm{~mm}$ (thickness). The extrusion ratio was 27:1 and the true strain was 3.3. The as-extruded alloy is denoted as " $\mathrm{F}$ ". 
Table 1. Composition of $6066 \mathrm{Al}$ alloy.

\begin{tabular}{cccccccc}
\hline Element & $\mathbf{M g}$ & $\mathbf{S i}$ & $\mathbf{C u}$ & $\mathbf{M n}$ & $\mathbf{F e}$ & $\mathbf{C r}$ & $\mathbf{A l}$ \\
\hline Mass $\%$ & 1.02 & 1.29 & 0.98 & 1.02 & 0.19 & 0.18 & Bal. \\
\hline
\end{tabular}

The salt bath for spheroidized grain formation was conducted at $620^{\circ} \mathrm{C}$ for 10 min and then cooled down by quenching in water. The grains were spheroidized uniformly and the fraction of liquid phases was high with these salt bath settings. The material deformed severely, or was partially melted severely, when the temperature was higher than $620^{\circ} \mathrm{C}$. The TS-SIMA alloy subjected to this salt bath is denoted as "S10".

Aluminum alloys are often fully annealed for subsequent manufacturing. Therefore, the test alloy in this study was fully annealed for comparison with TS-SIMA-processed specimens. In the full annealing treatment, $\mathrm{F}$ was heated to $420{ }^{\circ} \mathrm{C}$ for $2 \mathrm{~h}$, cooled to $220^{\circ} \mathrm{C}$ at a cooling rate of $25^{\circ} \mathrm{C} / \mathrm{min}$, and then cooled in a furnace to room temperature. The fully annealed $6066 \mathrm{Al}$ alloy is denoted as " $\mathrm{O}$ ".

The microstructural characteristics and grain size were analyzed using optical microscopy (OM). The specimens were polished using SIC papers from 80\# to 5000\# (the number before \# means how many hard particles in per square inch), $\mathrm{Al}_{2} \mathrm{O}_{3}$ aqueous suspension (1.0 and $0.3 \mu \mathrm{m}$ ), and $\mathrm{SiO}_{2}$ polishing suspension and etched using Keller's reagent. The liquid fraction of the lower-melting-point second phases was measured using ImageJ (National Institetes of Health, Java 1.8.0_60, New York, NY, USA) software. Two shape parameters, $x$ and $z$, were defined for the degree of spheroidization [5]. In Figure 2, $a, b, c$, and $A$ represent the major axis, minor axis, perimeter, and area of a grain, respectively. According to the definitions $x=(b / a)$ and $z=(4 \pi A) / c^{2}, x$ is the ratio of the minor axis to the major axis and $z$ becomes closer to 1 as the shape becomes more circular. As $x$ and $z$ become closer to 1 , the grains become more equi-axial and the degree of spheroidization increases.
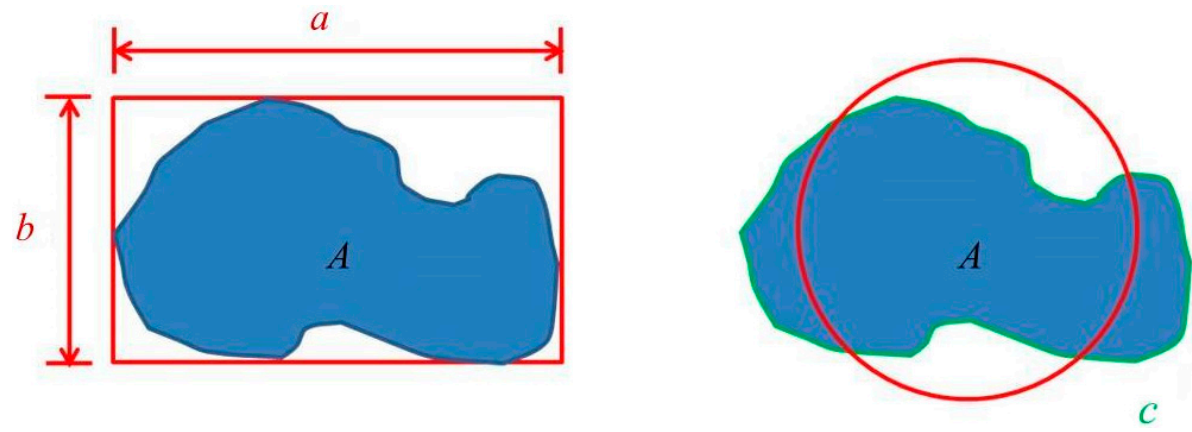

Figure 2. Parameters of spheroidization degree definition.

The hardness of the matrix and globular grain boundaries were evaluated using nano-indentation to understand the hardness distribution in the TS-SIMA alloys. A triangular pyramidal diamond probe was used for nano-indentation. The measurement conditions were a drift velocity of $0.25 \mathrm{~nm} / \mathrm{s}$ and a depth of $800 \mathrm{~nm}$. The space between measurement points was $5 \mu \mathrm{m}$.

In the high-temperature compression test, as-extruded alloys, fully-annealed alloys, and TS-SIMA alloys were tested to compare their high-temperature formability. The compression ratio is defined as $R \%=\left(t_{0}-t_{f}\right) / t_{0}$, where $t_{0}$ is the thickness of the initial sheet $(9 \mathrm{~mm})$ and $t_{f}$ is the thickness after compression. The specimens for compression had dimensions of $40 \mathrm{~mm}$ (length) $\times 20 \mathrm{~mm}$ (width) $\times 9 \mathrm{~mm}$ (thickness). The compression temperature was set as $600{ }^{\circ} \mathrm{C}$ and the compression rate was set as $20 \mathrm{~mm} / \mathrm{min}$. The compressive loadings of the different materials were estimated and compared as the compression ratio reached $50 \%$. When the compression ratio is higher, the deformation resistance is lower, which indicates better high-temperature formability [12]. The specimens compressed to a compression ratio of $50 \%$ were used in further experiments for improving the mechanical properties. Specimens subjected to compression are marked with the prefix "C-". 
Finally, in order to confirm that the mechanical properties of the compressed TS-SIMA alloys can be enhanced, T6 heat treatment was adopted. T6 heat treatment includes solution heat treatment and artificial aging. Solution temperatures of $530{ }^{\circ} \mathrm{C}$ and $550{ }^{\circ} \mathrm{C}$ were used in this research. Specimens subjected to T6 heat treatment are marked the suffix "T6 $6_{530}$ " or "T6 $6_{550}$ ". The hardness of the specimens was measured using a Rockwell hardness tester and the tensile properties were tested using a universal tester. The dimensions of the tensile test specimen are shown in Figure 3. The tensile specimen was prepared by a milling machine for thinning and wire cutting for shaping. The tensile initial strain velocity was $1.67 \times 10^{-3}$ (crosshead velocity of $1 \mathrm{~mm} / \mathrm{min}$ ). Each hardness and tensile datum was the average from at least three testing samples.

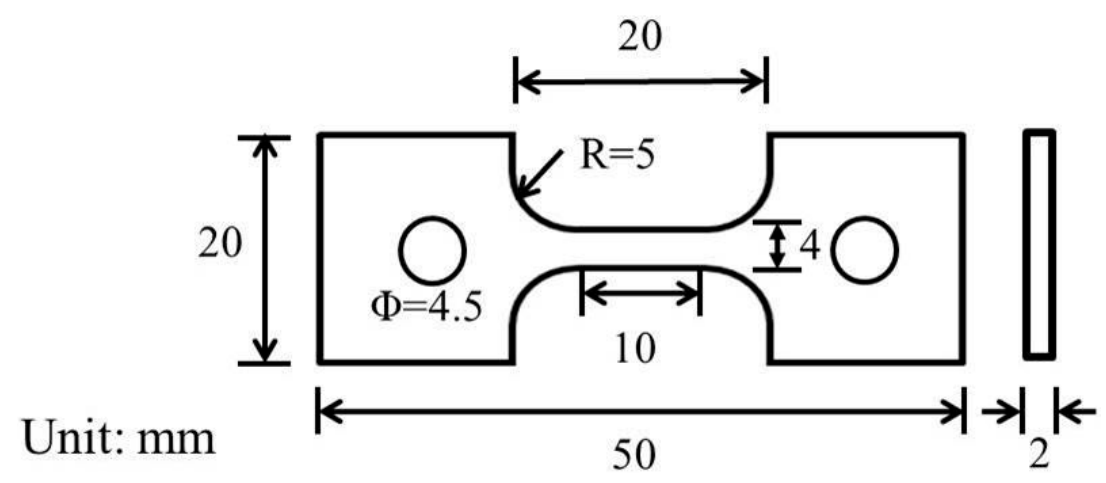

Figure 3. Dimensions of tensile test specimen.

\section{Results and Discussion}

\subsection{Microstructure Characteristics}

Figure 4 shows the microstructures of as-extruded alloys and TS-SIMA alloys. The typical extrusion microstructure can be seen in the metallography of the as-extruded alloys, as shown in Figure 4a. Dynamic recrystallization only occurred in parts of F; the recrystallized grain size was about 5-8 $\mu \mathrm{m}$. Grains were spheroidized uniformly after a salt bath for $10 \mathrm{~min}$. The average globular grain size was about $78 \mu \mathrm{m}$. The shape parameters $x$ and $z$ were 0.62 and 0.65 , respectively.

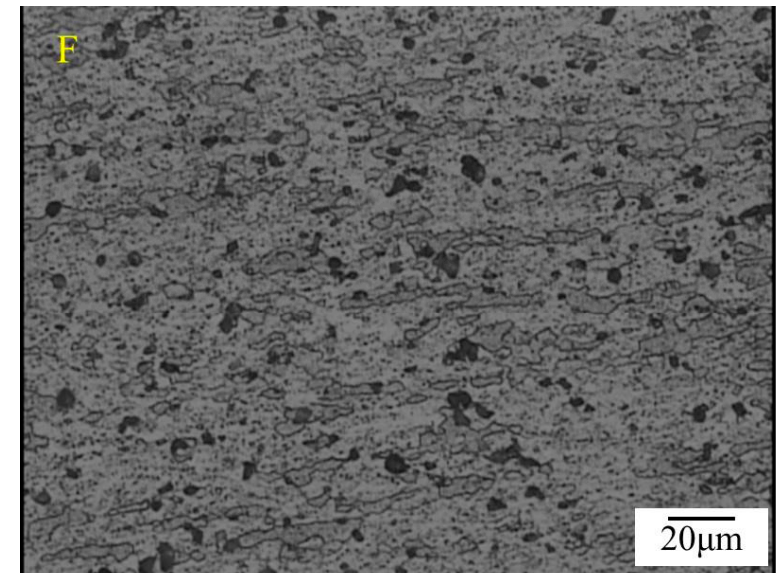

(a)

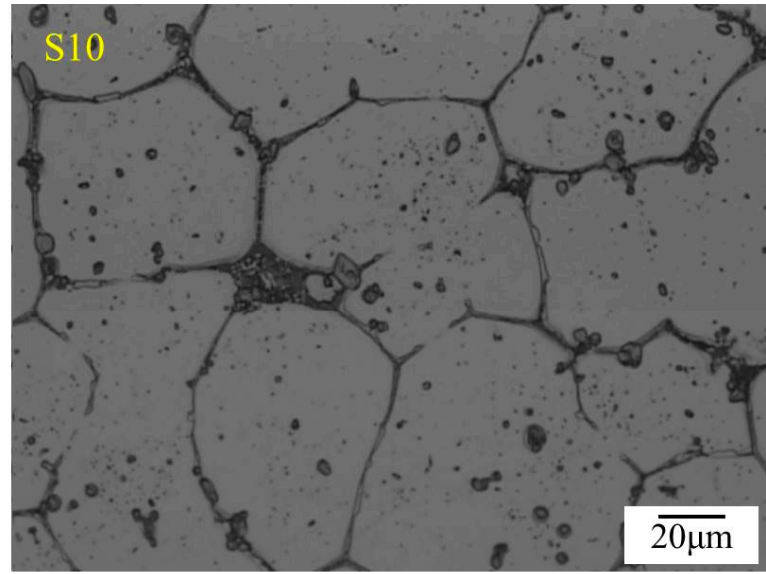

(b)

Figure 4. Microstructures of (a) as-extruded alloys (F) and (b) TS-SIMA alloys (S10).

The distribution of elements in S10 was analyzed using electron probe microanalysis (EPMA) (JEOL, Peabody, MA, USA). The results are shown in Figure 5. After a salt bath, Mg, Si, and Cu were located at the grain boundaries and formed a network structure, but Mn, Fe, and Cr just aggregated 
and formed a particle-shaped phase due to the melting point of the Mn-rich phase being higher than $620^{\circ} \mathrm{C}$ [13]. The phases at globular boundaries are composed of the eutectic phase of $\mathrm{Al}$ and $\mathrm{Al}_{2} \mathrm{Cu}$, the eutectic phase of $\mathrm{Al}$ and $\mathrm{Mg}_{2} \mathrm{Si}$, and the eutectic phase of $\mathrm{Al}$ and $\mathrm{Si}$. The melting points of these eutectic phases are below $620^{\circ} \mathrm{C}$ and, thus, they melted and penetrated into the globular grain boundaries.

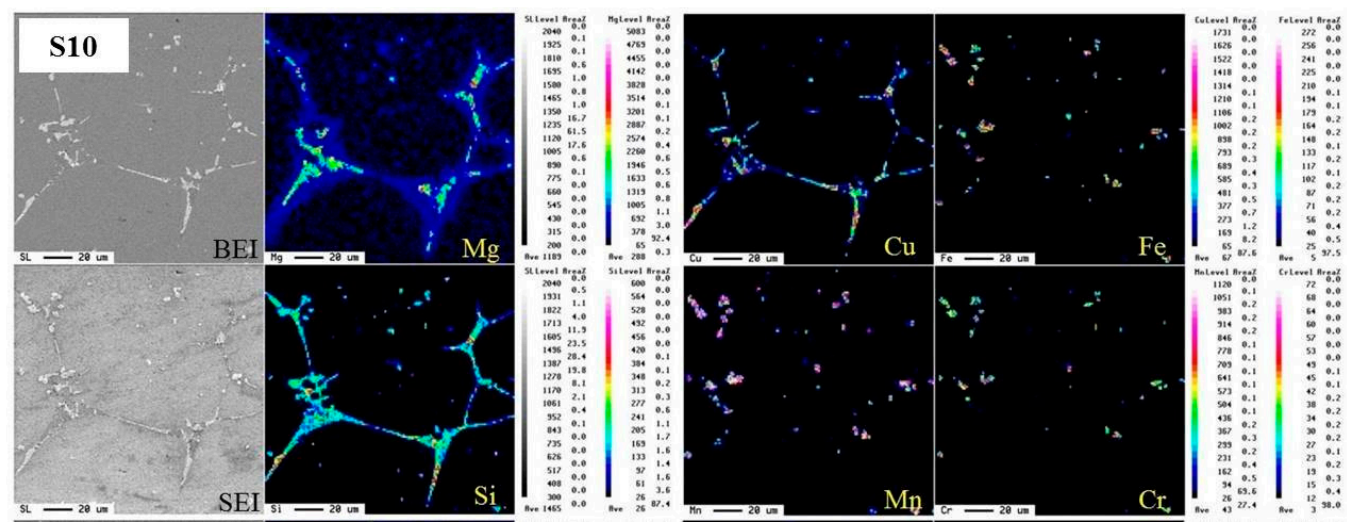

Figure 5. Elemental distribution of TS-SIMA alloy (S10) obtained using EPMA.

The nano-indentation data for S10 are shown in Figure 6. The same results were obtained for five samples. The spheroidized grain boundaries, abundant in $\mathrm{Cu}, \mathrm{Mg}$, and $\mathrm{Si}$, are much harder than the internal grains. This proves that the grain boundaries of the TS-SIMA alloy are the hard and brittle parts of the material. When a TS-SIMA alloy is defomed, the deformation should be where stress concentration occurs.

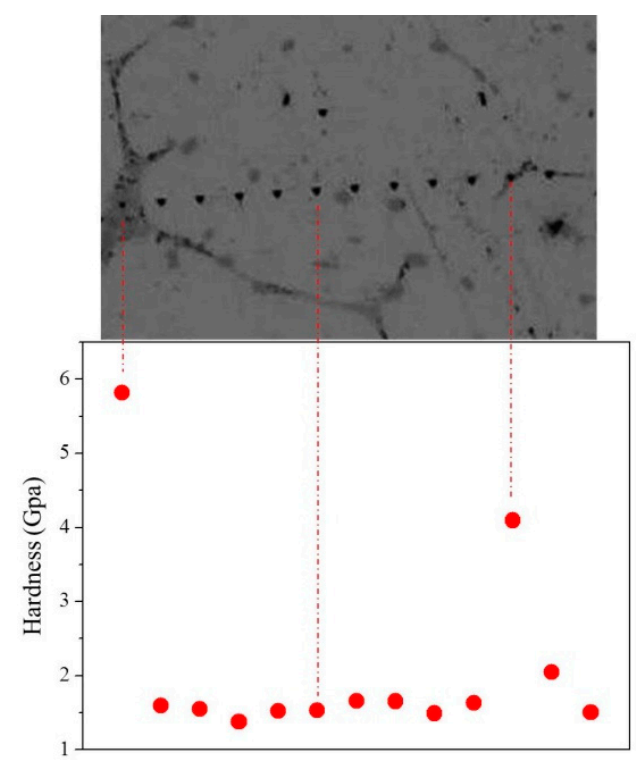

Figure 6. Hardness distribution in TS-SIMA alloys evaluated using nano-indentation.

\subsection{High-Temperature Compressive Resistance of TS-SIMA Alloy}

For the compression test at $600^{\circ} \mathrm{C}$, Figure 7 shows the compression loading at a $50 \%$ compression ratio for various materials. It can be seen that $\mathrm{S} 10$ has the lowest compression loading. Full annealing reduced compression loading by only about $9 \%$ but the TS-SIMA process reduced it by about 35\% compared with that of the as-extruded alloys. This proves that the TS-SIMA process is beneficial for 
enhancing high-temperature compressibility. The compressive resistance of the TS-SIMA alloy was the smallest.

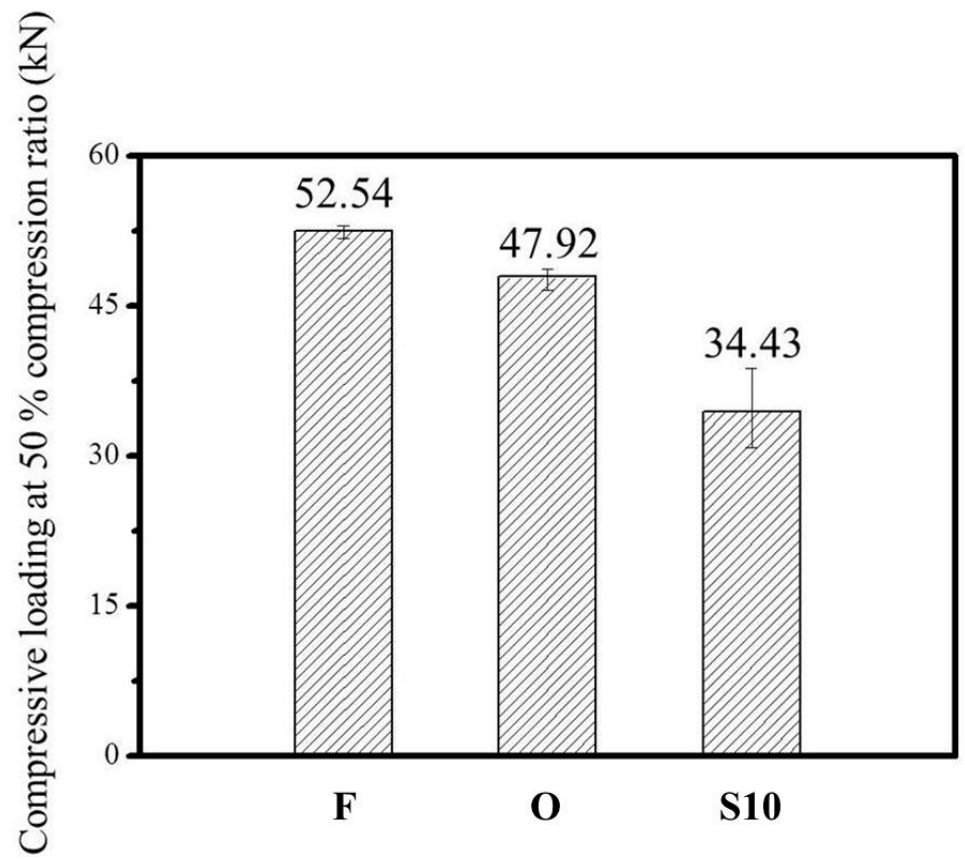

Figure 7. Deformation resistance of several materials.

Figure 8 shows the microstructures of compressed TS-SIMA alloys. It can be seen that after high-temperature compression, globular grains became flat and oval-shaped, as shown in Figure 8a. Under large magnification (Figure $8 \mathrm{~b}$ ), it can be seen that the original broad grain boundaries of the TS-SIMA alloys vanished after compression. Only Mn-rich particle phases existed at the grain boundaries and in the internal grains. This resulted from the low-melting-point phases at grain boundaries melting at $600{ }^{\circ} \mathrm{C}$ and flowing during high-temperature compression.

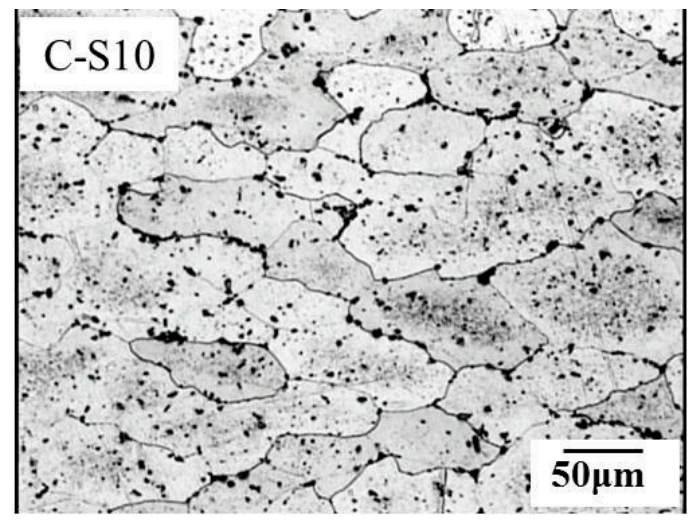

(a)

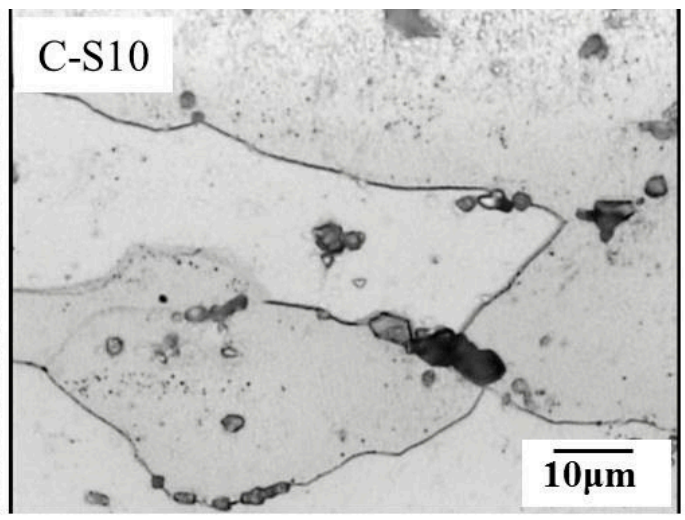

(b)

Figure 8. Microstructure of TS-SIMA alloy at (a) small and (b) large magnification.

Figure 9 shows the elemental distribution of compressed TS-SIMA alloys. It shows that $\mathrm{Cu}, \mathrm{Mg}$, and $\mathrm{Si}$ were no longer located at the globular grain boundaries after high-temperature compression. They diffused and solid-soluted into the matrix during hot-temperature compression. In contrast, Mn, $\mathrm{Fe}$, and $\mathrm{Cr}$ still aggregated and formed a particle-shaped phase. 

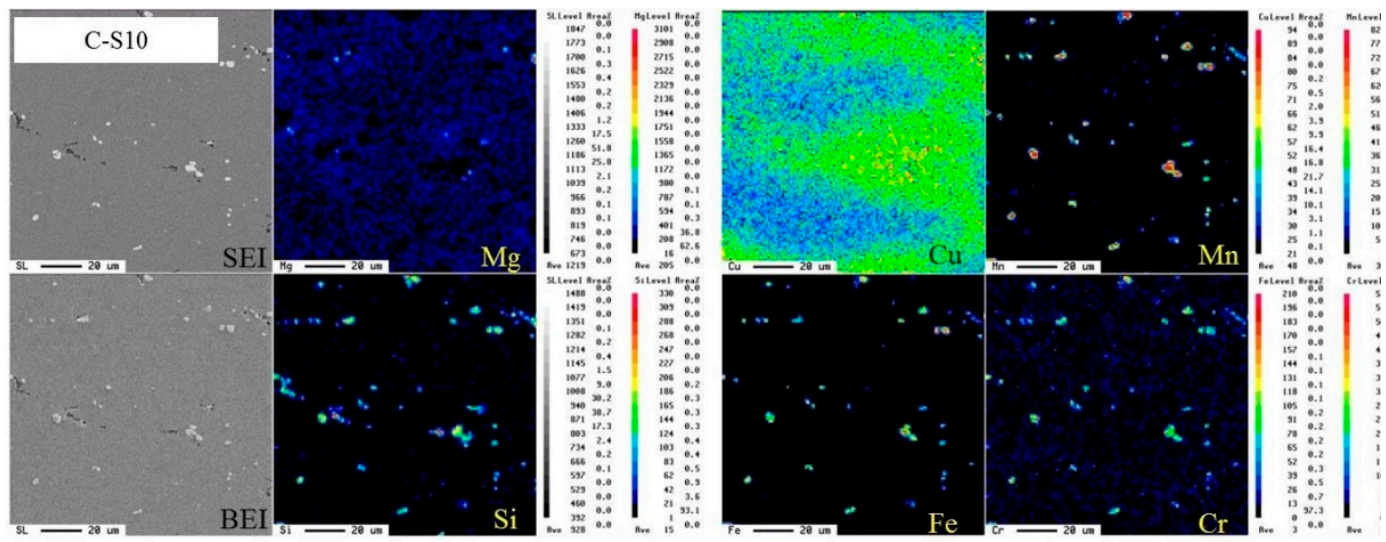

Figure 9. Elemental distribution of compressed TS-SIMA alloy (C-S) obtained using EPMA.

\subsection{Mechanical Properties Improvement of TS-SIMA Forming Alloys}

In order to ensure that the formed products are suitable for applications, the mechanical properties of compressed TS-SIMA alloys were investigated. T6 heat treatment, the most commonly used method for strengthening 6xxx series $\mathrm{Al}$ alloys, is used in this study. Figure 10 shows the hardness data and Figure 11a shows the tensile properties data of compressed and heat-treated materials. Hardness data show that the hardness values of as-extruded alloys and TS-SIMA alloys are similar. High-temperature compression significantly enhanced hardness. After T6 heat treatment, the hardness of all specimens increased obviously. Hardness increased with increasing solution heat treatment temperature due to the solution limit being enhanced by increased solution temperature. The hardness of compressed TS-SIMA alloys is slightly lower than that of as-extruded alloys after T6 heat treatment. Strength data trends are similar to those of hardness data. The strength of specimens increased after T6 heat treatment. The strength of compressed TS-SIMA alloys was slightly lower (by about 10-20 MPa) than that of as-extruded alloys. The ultimate tensile strength (UTS) of TS-SIMA alloys reached about 430-440 MPa. This shows that the strength of TS-SIMA forming materials after T6 heat treatment is high enough for common applications.

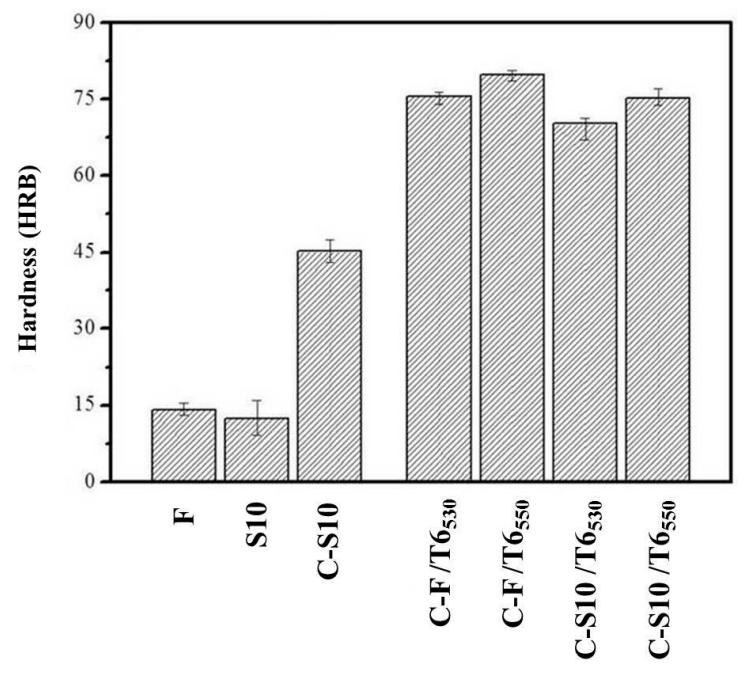

Figure 10. Hardness data of specimens.

Elongation data are shown in Figure 11b. The tensile elongation of TS-SIMA alloys is much lower than that of as-extruded alloys. Elongation can be improved to about $23 \%$ uniform elongation (UE) and $27 \%$ total elongation (TE) after compression at $600{ }^{\circ} \mathrm{C}$. The enhancement of elongation is majorly due 
to the hard and brittle phases located at globular boundaries composed of $\mathrm{Al}, \mathrm{Mg}$, $\mathrm{Si}$, and $\mathrm{Cu}$ diffused into matrix After T6 heat treatment, elongation increased with decreasing solution heat treatment temperature. Uniform elongation reached about $12 \%$ and total elongation reached $16 \%$ when the solution heat treatment temperature was $530^{\circ} \mathrm{C}$. Even though the elongation of TS-SIMA alloys was quite low, high-temperature compression improved it. The mechanical properties of TS-SIMA alloys can thus be improved by high-temperature compression and T6 heat treatment. Strength can reach more than $400 \mathrm{MPa}$ and elongation can reach more than $10 \%$ after appropriate heat treatment.

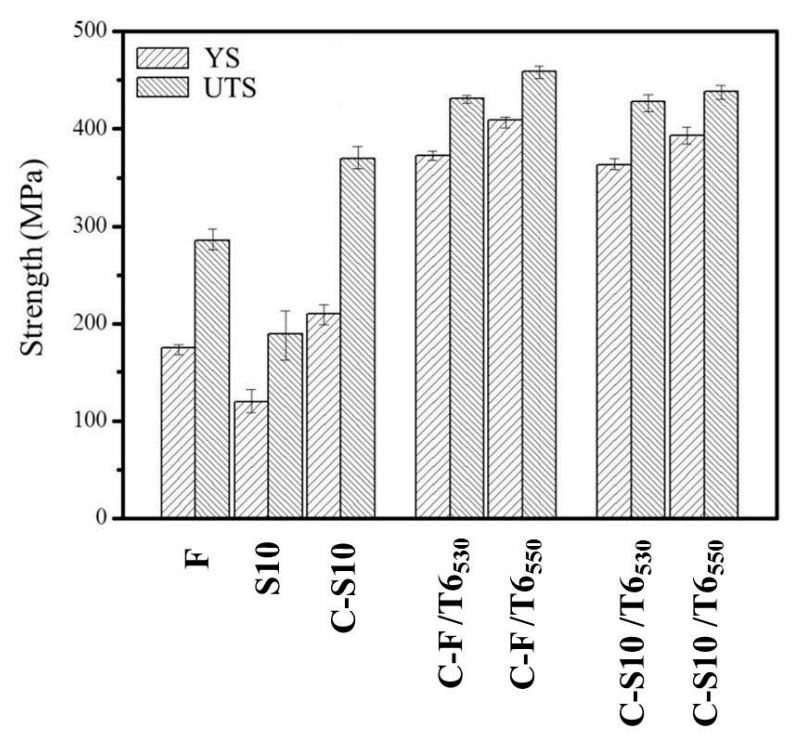

(a)

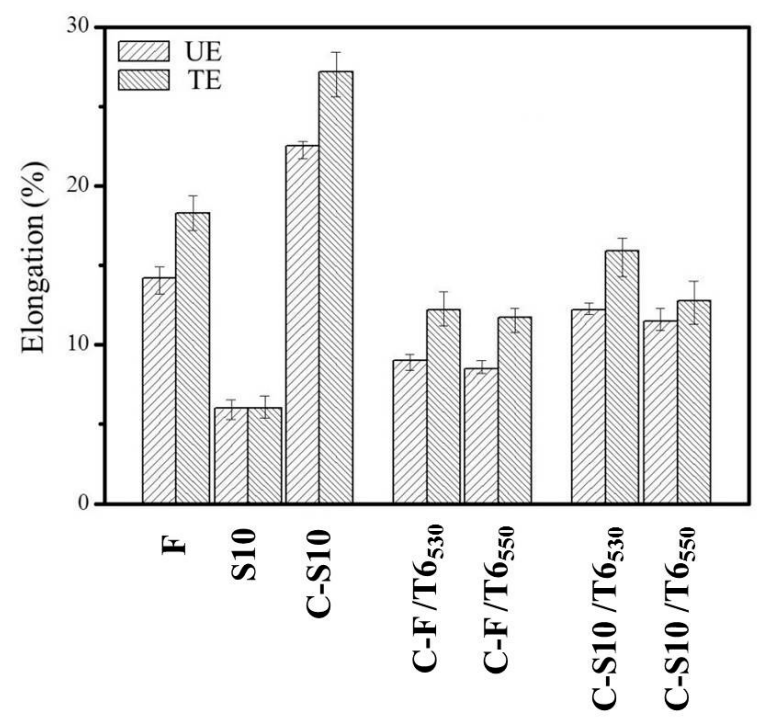

(b)

Figure 11. Mechanical properties of specimens: (a) tensile strength and (b) tensile elongation.

Figure 12 shows the microstructures of compressed TS-SIMA alloys after T6 heat treatment. It shows that the original compressed globular grains of compressed TS-SIMA alloys grew during solution treatment, as shown in Figure 12c,d. The microstructure of T6-heat-treated as-extruded alloys remained as fine recrystallized grains, as show in Figure 12e,f. The level of precipitation strengthening of compressed TS-SIMA alloys and as-extruded alloys should be similar because their compositions 
and T6 heat treatment conditions are the same. The slightly different mechanical properties are due to grain size according to Hall-Petch theory [14,15]. After T6 heat treatment, the strength of as-extruded alloys was higher than that of TS-SIMA forming alloys due to the former's fine grains. However, the high density of grain boundaries of T6-heat-treated as-extruded alloys slightly decreased elongation because dislocation slipping is restricted by grain boundaries. Therefore, the elongation of TS-SIMA forming alloys is higher than that of T6-heat-treated as-extruded alloys.

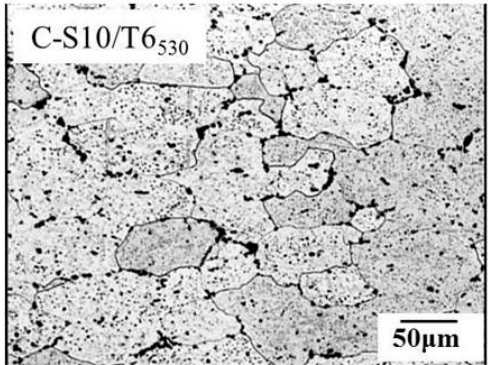

(a)

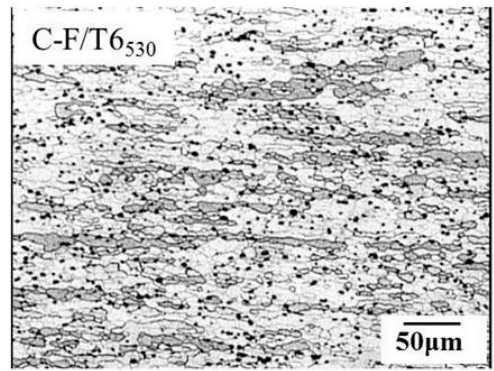

(c)

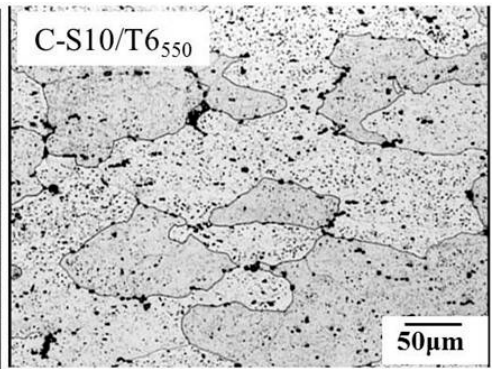

(b)

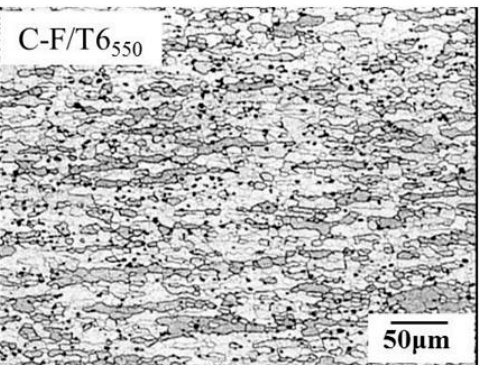

(d)

Figure 12. Morphologies of (a) C-S10/T6 $6_{530} ;$ (b) C-S10/T6 $550 ;$ (c) C-F/T6 530 ; and (d) C-F/T6 550 .

Figure 13 shows the elemental distribution of compressed TS-SIMA alloys after T6 heat treatment. It shows that all elements were distributed uniformly. This proves that T6 heat treatment made $\mathrm{Cu}$, $\mathrm{Mg}$, and Si solid-solute completely and precipitate.
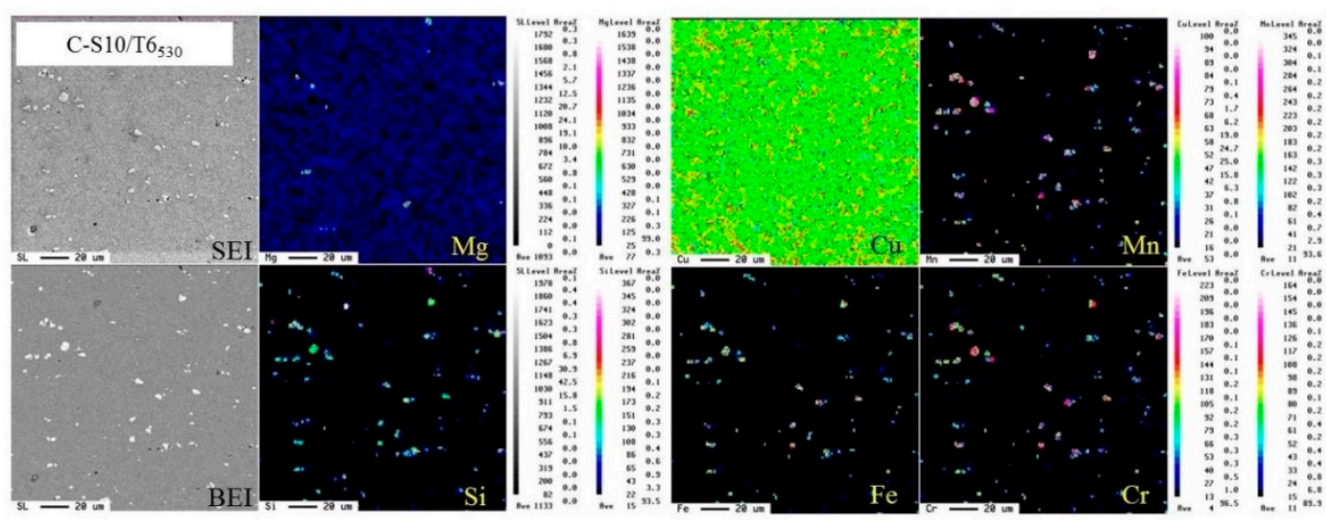

Figure 13. Elemental distribution of compressed TS-SIMA alloy after T6 heat treatment (C-S10/T6530) obtained using EPMA.

The fracture mechanism of the above specimens can be interpreted from Figures 14 and 15. Figures 14a and 15a show the intergranular fracture characteristics of TS-SIMA alloys. The low-melting-point phases melted, penetrated, and solidified at globular grain boundaries, resulting in the grain boundary being more brittle and harder than the matrix. This led to stress concentration and the generation of 
cracks. The cracks initiated at grain boundaries and connected with each other, leading to intergranular fracture. In contrast, characteristic dimple fractures were found on the fracture surfaces of compressed TS-SIMA alloys and T6-heat-treated compressed TS-SIMA alloys, as shown in Figure 14c-f. Micro-void coalescence and ductile fracture caused these dimple fractures. The sub-surface morphologies of compressed TS-SIMA alloys and T6-heat-treated compressed TS-SIMA alloys are shown in Figure 15b-d. Intergranular fractures did not appear because the brittle and low-melting-point phases vanished after high-temperature compression. Therefore, good mechanical properties were obtained.

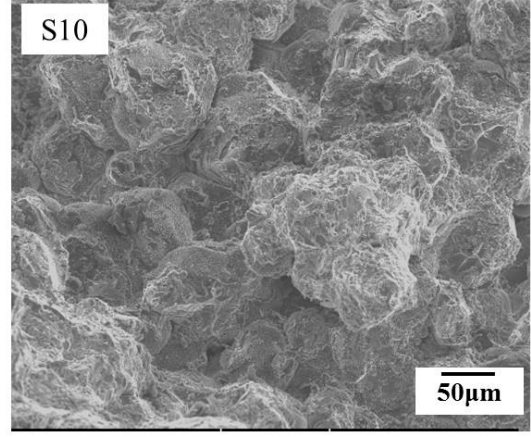

(a)

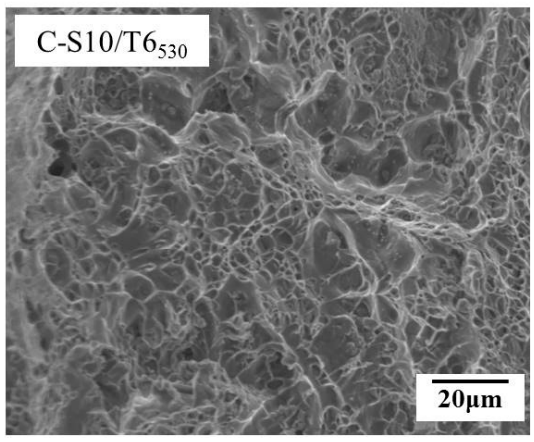

(c)

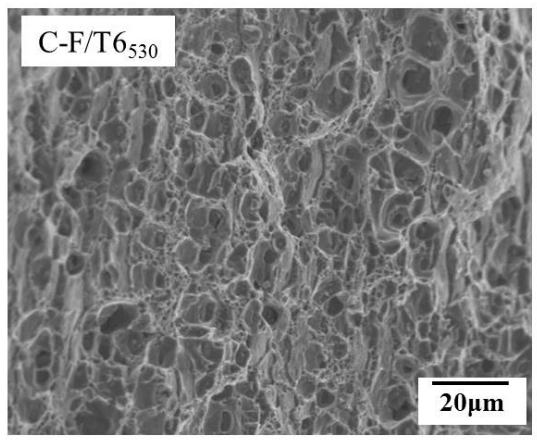

(e)

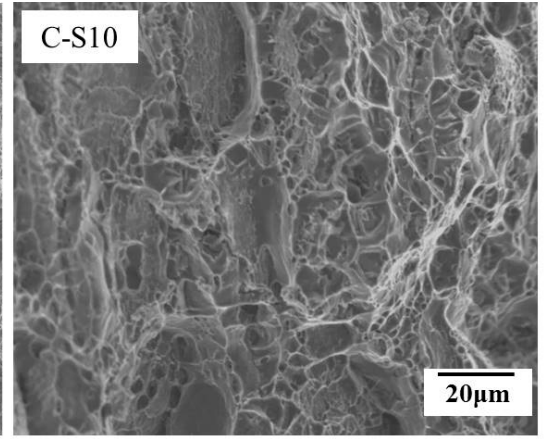

(b)

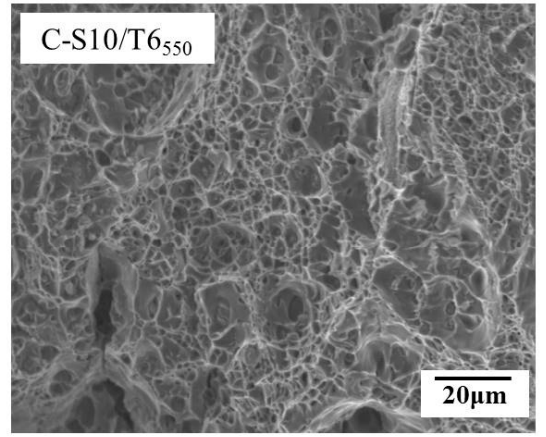

(d)

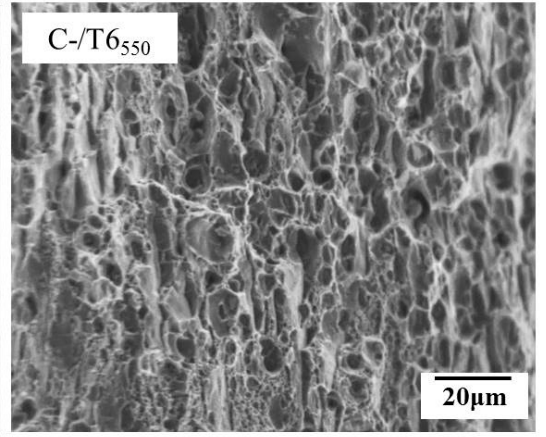

(f)

Figure 14. Fracture surfaces of (a) S10; (b) C-S10; (c) C-S10/T6 530 ; (d) C-S10/T6 550 ; (e) C-F/T6 530 ; and (f) C-F/T6550.

Brittle and hard phases located at the grain boundaries of TS-SIMA alloys disappeared after high-temperature compression, improving elongation. Total elongation increased to about $30 \%$. After T6 heat treatment, the tensile strength of TS-SIMA forming alloys reached about $430 \mathrm{MPa}$. The strength of such alloys is slightly less than that of T6-heat-treated as-extruded alloys (by about $20 \mathrm{MPa}$ ) and its elongation can be slightly higher than that. The mechanical properties of T6-heat-treated TS-SIMA forming alloys are sufficient for common applications. 


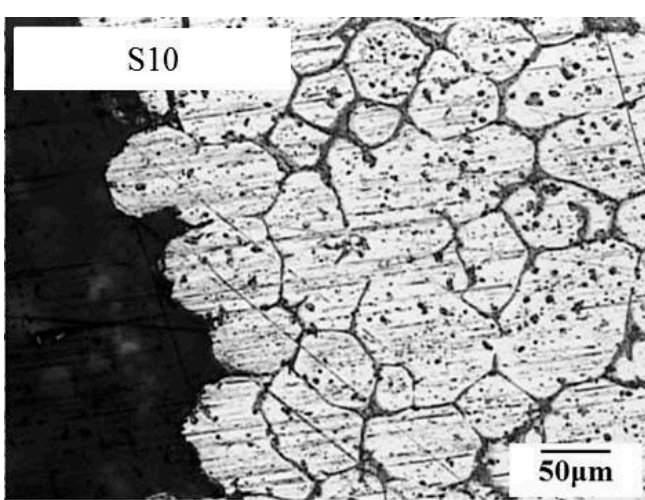

(a)

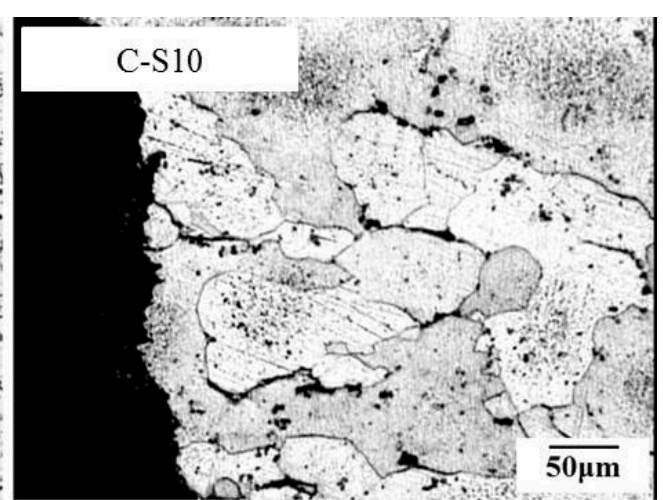

(b)

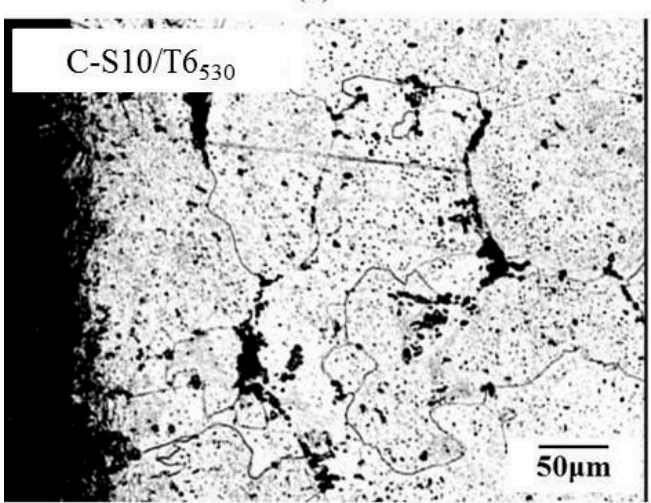

(c)

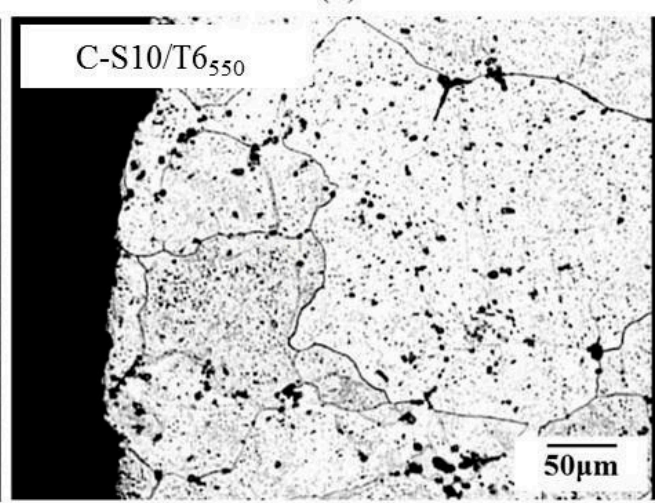

(d)

Figure 15. Sub-surfaces of (a) S10; (b) C-S10; (c) C-S10/T6 530 ; and (d) C-S10/T6 550 .

\section{Conclusions}

(1) Globular grains were obtained using the TS-SIMA process. After a salt bath, the grains became globular and $\mathrm{Cu}, \mathrm{Mg}$, and $\mathrm{Si}$ were the major elements distributed on the globular grain boundaries. The globular grain boundaries were harder than the $\mathrm{Al}$ matrix.

(2) High-temperature compressive resistance can be reduced by the TS-SIMA process. With a $50 \%$ compression ratio, the TS-SIMA process decreased compression loading by about $35 \%$. After high-temperature compression, $\mathrm{Cu}, \mathrm{Mg}$, and $\mathrm{Si}$ were no longer located at the compressed globular grain boundaries.

(3) High-temperature compression can improve the elongation of TS-SIMA alloys. The mechanical properties of TS-SIMA alloys can be enhanced by T6 heat treatment. The mechanical properties are sufficient for common applications.

Acknowledgments: The authors are grateful to the Instrument Center of National Cheng Kung University and the National Science Council of Taiwan (NSC MOST103-2221-E-006-056-MY2) for their financial support.

Author Contributions: Chia-Wei Lin, designed the experiments, performed the experiments, analyzed the data and wrote the paper; Fei-Yi Hung and Truan-Sheng Lui gave suggestions for improving experiments and analysis.

Conflicts of Interest: The authors declare no conflict of interest.

\section{References}

1. Hatch, J.E. Aluminum: Properties and Physical Metallurgy; ASM International: Materials Park, OH, USA, 1984; Volume 1, p. 50.

2. Zhen, L.; Fei, W.D.; Kang, S.B.; Kim, H.W. Precipitation behavior of Al-Mg-Si alloys with high silicon content. J. Mater. Sci. 1997, 32, 1895-1902.

3. Fan, Z. Semisolid metal processing. Int. Mater. Rev. 2002, 47, 49-85. [CrossRef] 
4. Song, Y.B.; Park, K.T.; Hong, C.P. Recrystallization behavior of $7175 \mathrm{Al}$ alloy during modified strain-induced melt-activated (SIMA) process. Mater. Trans. 2006, 47, 1250-1256. [CrossRef]

5. Tzimas, E.; Zavaliangos, A. A comparative characterization of near-equiaxed microstructures as produced by spray casting, magnetohydrodynamic casting and the stress induced, melt activated process. Mater. Sci. Eng. A 2000, 289, 217-227. [CrossRef]

6. Paes, M.; Zoqui, E.J. Semi-solid Behavior of New Al-Si-Mg Alloys for Thixoforming. Mater. Sci. Eng. A 2005, 406, 63-73. [CrossRef]

7. Parshizfard, E.; Shabestari, S.G. An investigation on the microstructural evolution and mechanical properties of A380 aluminum alloy during SIMA process. J. Alloy. Compd. 2011, 509, 9654-9658. [CrossRef]

8. Akhlaghi1, F.; Farhood, A.H.S. Characterization of globular microstructure in NMS processed aluminum A356 alloy: The role of casting size. Adv. Mater. Res. 2011, 264-265, 1868-1877. [CrossRef]

9. Tzimas, E.; Zavaliangos, A. Evolution of near-equiaxed microstructure in the semisolid state. Mater. Sci. Eng. A 2000, 289, 228-240. [CrossRef]

10. Emamy, M.; Razaghian, A.; Karshenas, M. The effect of strain-induced melt activation process on the microstructure and mechanical properties of Ti-refined A6070 Al alloy. Mater. Des. 2013, 46, 824-836. [CrossRef]

11. Lin, C.W.; Hung, F.Y.; Lui, T.S. High-temperature deformation resistance and forming behavior of two-step SIMA-processed 6066 alloy. Mater. Sci. Eng. A 2016, 659, 143-157. [CrossRef]

12. Lee, K.S.; Kim, S.; Lim, K.R.; Hing, S.H.; Kim, K.B.; Na, Y.S. Crystallization, High temperature defroemation behavior and solid-to-solid formability of a Ti-based bulk metallic glass within supercooled liquid region. J. Alloy. Compd. 2016, 663, 270-278. [CrossRef]

13. ASM International Alloy Phase Diagram and the Handbook Committees. ASM Handbook; ASM International: Materials Park, OH, USA, 1992; Volume 3, pp. 307-308.

14. Hall, E.O. The deformation and ageing of mild steel. Proc. Phys. Soc. 1951, 64, 747-753. [CrossRef]

15. Petch, N.J. The cleavage strength of polycrystals. J. Iron Steel Int. 1953, 174, 25-28.

(C) 2016 by the authors; licensee MDPI, Basel, Switzerland. This article is an open access article distributed under the terms and conditions of the Creative Commons Attribution (CC-BY) license (http://creativecommons.org/licenses/by/4.0/). 